\title{
ENGINEERING OF CYCLIC PEPTIDES WITH NOVEL INHIBITING PROPERTIES TO DIFFERENTIATE TWO SERINE PROTEASES, CHYMOTRYPSIN AND SUBTILISIN CARLSBERG
}

\author{
Shui-Tein Chen'", Maw-Tsiung Yang ${ }^{3}$, Chi-Yue Wu ${ }^{2}$, Kung-Tsung Wang 1.2.3.* \\ 1. Institute of Biological Chemistry, Academia Sinica \\ 2. Department of Chemistry, National Taiwan University \\ 3. Institute of Biochemical Sciences, National Taiwan University
}

Based on the crystal structure of the inhibitory l(x)p of barley chymotrypsin inhibitor II (Cl-II), two cyclic peptides, $\mathbb{l}-\mathbf{l}$ and $\mathbf{l}-2$, were designed and synthesized chemically. $\underline{I}-\mathbf{l}$ is a noncompetitive inhibitor for chymotrypsin and an uncompetitive inhibitor for subtilisin Carlsberg. I- 2 exhibited competitive inhibition of both chymotrypsin and subtilisin Carlsberg. The results indicate that the hydrophobic region of the inhibitory loop of Cl-II plays an important role for $\mathrm{Cl}-\mathrm{II}$ to bind to the active sites of proteases.

The design of conformationally constrained peptides or proteins is a powerful method to elucidate the interaction of biologically active peptides and their receptors. ${ }^{1}$ The accumulated information of protein structures, advanced computer methods, and mature synthetic technique have increased the ease with which novel sequences can be prepared. ${ }^{2}$ Figure 1 shows the 3-D structure of the complex of subtilisin Carlsberg (thin line) and barley Chymotrypsin inhibitor 11 (CI-1I, thick line). Figure 1-b shows rotation by $90^{\circ}$ about the z-axial from Figure 1-a. The complex structure shows that only the inhibitory loop (54-69) of $\mathrm{Cl}-1 \mathrm{l}$ interacts with the active site region of subtilisin Carlsberg with Met-59 of Cl-II occupying the s-1 subsite, and that residues 56-61 of CI-Il are in close contact with subtilisin Carlsberg ${ }^{3}$ (distance less than $4 \mathrm{~A}$ ).

Fig 1-a

Fig 1-b
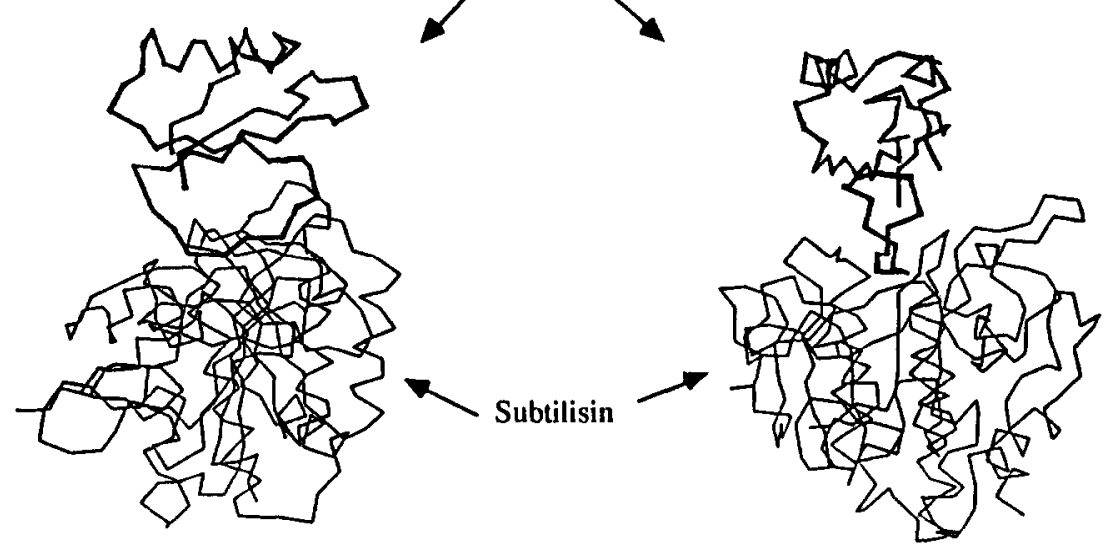
Figure 2 shows the amino acid sequence of the inhibitory loop (54-69) of CI-II and the major interactions between CI-II and subtilisin Carlsberg. The inhibitory loop of CI-II has two very distinct regions, one hydrophilic and the other hydrophobic, responsible for stabilizing the inhibitory loop of CI-II. Besides these interactions, there are backbone hydrogen bonds ( $>\mathrm{C}=\mathrm{O}--\mathrm{H}-\mathrm{N}<$ ) between $\mathrm{Cl}-\mathrm{II}$ and subtilisin Carlsberg (for example,Val-57 and Gly-127, Thr-58 and Gly-100, and Tyr-61 and Asn-218). All other residues of $\mathrm{CI}-\mathrm{Il}$ are responsible for holding the conformation of the inhibitory loop of CI-II.

Figure. 2 Partial structure of Chymotrypsin Inhibitor 2.

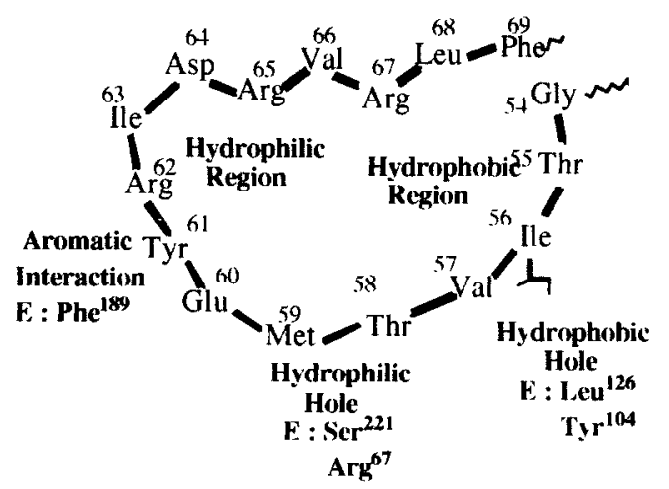

Figure. 3. 2-D structure of designed inhibitor-1 and inhibitor-2.

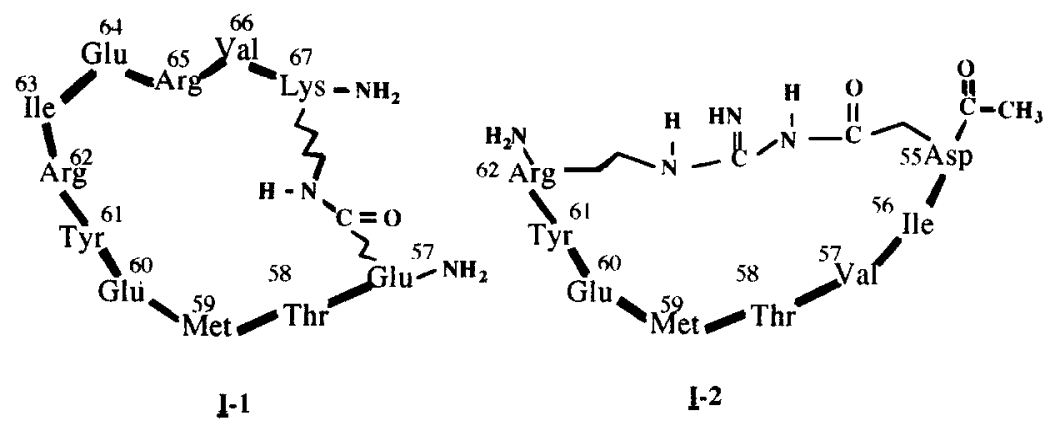

Based on this information, we rationally designed and synthesized two cyclic peptides: $\mathrm{H}_{2} \mathrm{~N}$ Glu-Thr-Met-Glu-Tyr-Arg-Ile-Glu-Arg-Val-Lys-NH $\mathrm{NH}_{2}$ (I-2), using the crystal structure of the inhibitory loop (53-70) of the CI-II as a template ${ }^{4-6}$ and a solid-phase peptide synthesis. For $\mathbf{l}-1$, the hydrophobic region of the inhibitory loop was truncated and a side-chain linkage was introduced between residues Glu-57 and Lys-67 to maintain the lowp structure by replacing Val-57 and Arg-67 by Glu and Lys, respectively, to evaluate the role of the hydrophobic region of the inhibitory loop in the inhibition of protease. Minimization of the force-field energy of $1-1$ 
structure with Insightll/Discover indicated that the side-chains of Lys-67 and Glu-57 formed an amide bond without disturbing the conformation of the backbone of I- 1. Asp-64 was changed to Glu to make the side-chain carboxyl group form a good ionic bond with the guanidine group of Arg-62 and to stabilize the loop structure. For $\mathbf{1 - 2}$, we constructed an amide bond to maintain the ring structure of CI-II and truncated residues 53-54 and 63-70 of the inhibitory loop to evaluate the role of these truncated residues in inhibition of protease. Therefore, Thr-55 was replaced by Asp to introduce a side-chain linkage between Asp-55 and Arg-62 and the N-terminal of Asp-55 was acetylated to increase the hydrophobic interaction with residues Leu-126 and Tyr-104 of subtilisin Carisberg.

The cyclic peptides were synthesized using solid-phase techniques on a benzhydrylamine resin ${ }^{7}$ and cyclized on resin according to an established method. ${ }^{8}$ The $\mathrm{N}^{\alpha}$-amino group of each amino acid residue was protected with the Fmoc-group; for L- 1 the side chain of Lys-67 was protected with the Boc-group, and side chain of Glu-57 and Thr-58 were protected with $\mathrm{t}-\mathrm{Bu}$. Side chains of all other residues were protected with a TFA-resistance group [ i.e. Arg(Tos), Glu(Bzl)]. For $\mathbf{L}-2$ the side chain of Asp-57, Thr-60 and Tyr-63 were protected with t-Bu, of Glu-62 was protected with Bzl and the side-chains of Arg-64 with Mtr. The synthesis was started from resin (1.0 g, amino-content 0.60 $\mathrm{mmol} / \mathrm{g}$ ) and Fmoc-Lys(Boc)-OH (0.1 mmol). Based on the amino acid analysis nearly $100 \%$ of the, resin $(\sim 0.10 \mathrm{mmol} / \mathrm{g})$ was coupled. The rest of the unreacted amino group was acetylated with acetic anhydride/pyridine at $25^{\circ} \mathrm{C}$. After completion of chain elongation, the side-chain protecting groups of Glu(t-Bu) and $\mathrm{Lys}(\mathrm{Boc})$ were deprotected with TFA treatment, and cyclization on the resin was subsequently achieved at $25^{\circ} \mathrm{C}$ in $\mathrm{N}$-methylpyrrolidone with BOP (6 equivalents)/diisopropylethylamine (1\%) as the coupling reagent. ${ }^{9}$ It took $24 \mathrm{~h}$ for the cyclic peptide to complete formation of the side-chain amide bond. The Fmoc-group was deprotected with piperidine, and all other protecting groups were cleaved from the resin on treatment with HF. The crude peptide obtained was purified via gel filtration using TSK-gel (HW-40S, $47 \times 560 \mathrm{~mm}, 1 \%$ acetic acid) and the pooled fractions were further purified via preparative HPLC (vadyc RP-18 column, $2.0 \times 250 \mathrm{~mm}, 0.1 \%$ TFA in water/ $\mathrm{CN}_{3} \mathrm{CN} 35 / 65 \mathrm{v} / \mathrm{v}$ ) to yield pure peptide (I-1, $284 \mathrm{mg}$; overall yields $74 \%$. I-2: $179 \mathrm{mg}$, overall yield 67\%). The structure was confirmed by amino acid composition analysis and Fab mass spectra.

The inhibition parameters $k_{\mathrm{l}}$ of these two cyclic peptides for serine proteinases of two kinds chymotrypsin and subtilisin Carlsberg were measured at $25^{\circ} \mathrm{C}$. Kinetic test of inhibitors binding to Chymotrypsin and subtilisin Carlsberg were performed in Tris- $\mathrm{HCl}$ buffer containing Suc-Ala-Ala-ProPhe-pNA $(0.53 \mathrm{mM})$ with inhibitors at various concentrations and were monitored by the increased absorbance at $407 \mathrm{~nm}$ due to release of p-nitroalinine. To determine the inhibition kinetics the initial rates were measured spectrophotometrically and fit the results to the Michaelis-Menten equation with a nonlinear 
least-squares computer program. The concentrations of the inhibitor used in the assay and the results of inhibitory parameter of $\underline{I}-1$ and $\underline{I}-2$ on inhibition of the hydrolysis of Suc-Ala-Ala-Pro-Phe-pNA catalyzed by subtilisin carlsberg and chymotrypsin are listed in Table 1.

Table 1 . Observed parameter $\mathrm{k}_{1}$ for inhibition of subtilisin Carlsberg and chymotrypsin.

\begin{tabular}{|c|c|c|c|c|}
\hline & \multicolumn{4}{|c|}{ Subtilisin Carlsberg } \\
\hline & $\mathrm{V}_{\max } \mathrm{Ms}^{-1}$ & $\mathrm{k}_{\mathrm{m}} / \mathrm{M}$ & $\mathrm{k}_{\mathrm{car}} / \mathrm{s}^{-1}$ & $\mathrm{k}_{1} / \mathrm{M}$ \\
\hline no inhibitor & $2.94 \times 10^{-7}$ & $3.91 \times 10^{-4}$ & 890.91 & \\
\hline $1-1=300 \mathrm{nM}$ & $2.12 \times 10^{-7}$ & $2.79 \times 10^{-4}$ & 642.42 & $7.75 \times 10^{-7}$ \\
\hline $\bar{I}-\mathbf{I}=690 \mathrm{nM}$ & $1.57 \times 10^{-7}$ & $2.07 \times 10^{-4}$ & 457.76 & $7.86 \times 10^{-7}$ \\
\hline $\bar{I}-2=23 \mathrm{nM}$ & $2.86 \times 10^{-7}$ & $4.49 \times 10^{-4}$ & 886.67 & $1.28 \times 10-7$ \\
\hline \multirow[t]{3}{*}{$\mathbf{L} \mathbf{2}=138 \mathrm{nM}$} & $2.85 \times 10^{-7}$ & $8.31 \times 10^{-4}$ & 863.64 & $1.16 \times 10-7$ \\
\hline & \multicolumn{4}{|c|}{ Chymotrypsin } \\
\hline & $\mathrm{V}_{\max } / \mathrm{Ms}^{-1}$ & $\mathrm{k}_{\mathrm{rm}} / \mathrm{M}$ & $\mathbf{k}_{\mathrm{cat}} / \mathrm{s}^{-1}$ & $\mathrm{k}_{\mathrm{l}} \mathrm{M}$ \\
\hline no inhibitor & $4.59 \times 10^{7}$ & $3.07 \times 10^{-4}$ & 65.01 & \\
\hline $\mathbf{L} \mathbf{I}=120 \mathrm{nM}$ & $3.89 \times 10^{-7}$ & $3.10 \times 10^{-4}$ & 55.10 & $6.68 \times 10^{7}$ \\
\hline $\mathbf{L}-\mathbf{1}=276 \mathrm{nM}$ & $3.23 \times 10^{-7}$ & $2.98 \times 10^{-4}$ & 45.75 & $6.56 \times 10^{-7}$ \\
\hline $\bar{L}-2=69 \mathrm{nM}$ & $4.57 \times 10^{-7}$ & $4.09 \times 10^{-4}$ & 64.73 & $2.03 \times 10^{-7}$ \\
\hline $\mathbf{L} \mathbf{2}=138 \mathrm{nM}$ & $4.51 \times 10^{-7}$ & $5.20 \times 10^{-4}$ & 63.88 & $1.91 \times 10^{-7}$ \\
\hline
\end{tabular}

Figure 4 shows double-reciprocal plots for hydrolysis of Suc-Ala-Ala-Pro-Phe-pNA with inhibitors at various concentrations. $I-1$ exhibited as a noncompetitive inhibitor with $k_{1} \sim 6.7 \times 10^{-7}$ for Chymotrypsin and exhibited as an uncompetitive inhibitor with $\mathrm{k}_{1} \sim 7.8 \times 10^{7}$ for subtilisin Carlsberg. I- 2 exhibited as a competitive inhibitor for both enzymes with $k_{1} \sim 6.7 \times 10^{-7}$ for Chymotrypsin and $k_{1} \sim 7.8 \times 10^{7}$ for subtilisin Carlsberg.

Using compute programs Docking energy to calculate the interaction energy of enzyme and substrate and Total energy to estimate the stability of the complex of enzyme and ligand, we examined the kinetic properties of the inhibitor and the enzyme. Superimposing $\mathbf{I}-\mathbf{1}$ and $\mathbf{L}-\mathbf{2}$ with the interaction loop of CI-II we found that all backbone of the three peptides coincided well but orientations of the side-chain were extended in various directions. Docking $\mathbf{L}-\mathbf{1}$ and $\mathbf{L}-\mathbf{2}$ into the active site of subtilisin Carlsberg respectively caused many residues in I- 1 to bump into the residues near the active site of subtilisin Carlsberg. Table II shows the calculated docking and total energies of $\mathbf{L} \mathbf{1}$ and $\mathbf{L} \mathbf{2}$ in the active site of subtilisin Carlsberg according to the programs Insight II \& Discover (Biosym Inc). Results show that the calculated energy of the complex of $\mathbf{L} \mathbf{l}$ is so large that $\mathbf{L} \mathbf{1}$ is hard to mount at the active site of the subtilisin Carlsberg but can interact with amino acid residues that surround the active site of subtilisin Carlsberg. in contrast, the calculated energies of $\mathbf{L} \mathbf{2}$ and of CI-II are very similar and small. Thus $\mathbf{L} 2$ can easily mount into the active site and form a stable complex with the subtilisin. 

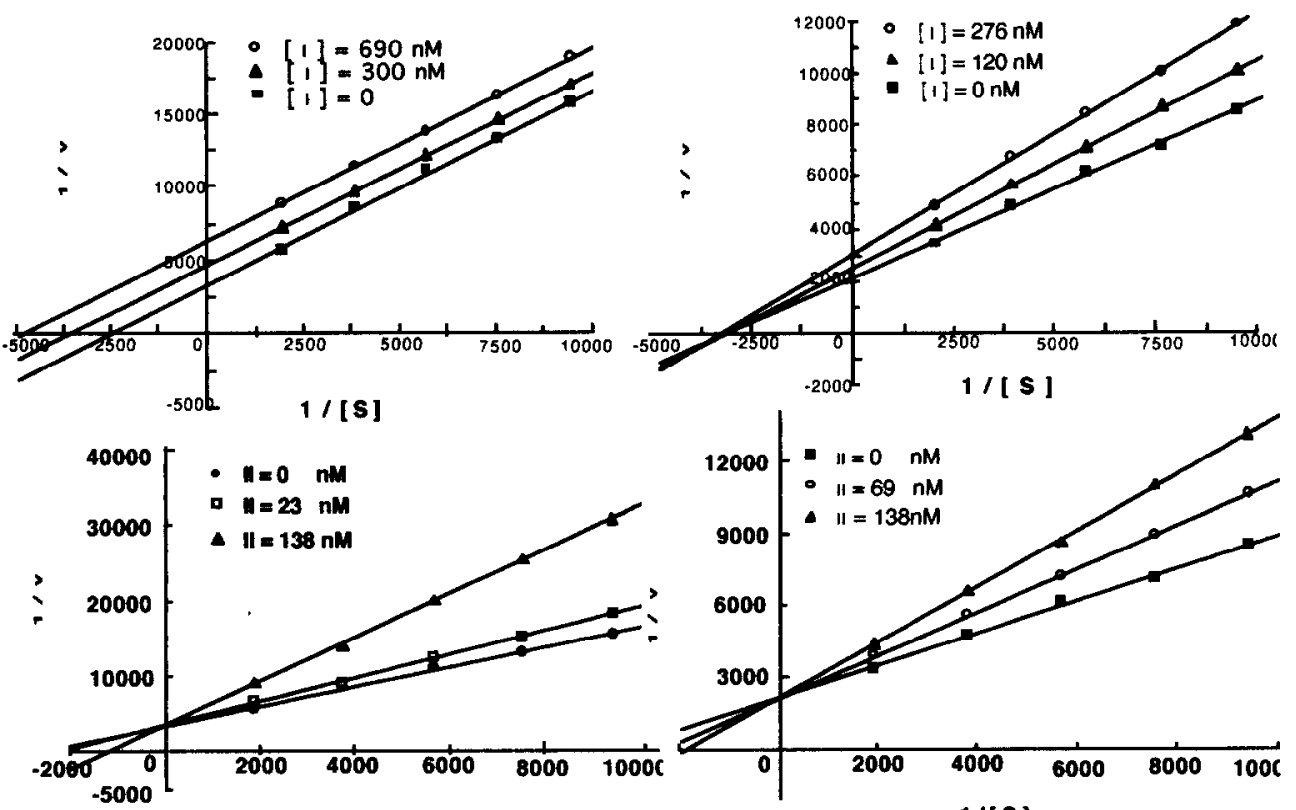

Figure 4. Double-reciprocal plots for Inhibiting assay of Chymotrypsin, and subtilisin Carlsberg-catalyzed hydrolysis of Suc-Ala-Ala-Pro-Phe-pNA in the presence of inhibitors. The assay was performed in

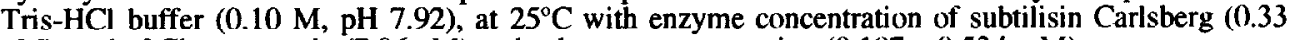
$\mathrm{nM})$, and of Chymotrypsin $(7.06 \mathrm{nM})$ and substrate concentration $(0.107 \sim 0.534 \mathrm{mM})$.

Fig 4-a. Subtilisin Carlsberg-catalyzed reaction in the presence of inhibitors ([0], [300], and $[690) \mid \mathrm{nM})$.

Fig 4-b. Chymotrypsin-catalyzed kinetic assay in the presence of inhibitors ([0], [120], and [276] nM). Fig 4-c. Subtilisin Carlsberg-catalyzed assay in the presence of inhibitors ([0], [300], and [690] nM)s. Fig 4-d. Chymotrypsin-catalyzed kinetic assay in the presence of inhibitors ([0], [120], and [276] nM).

Table II. Total energy and docking energy $/ \mathrm{kcal} / \mathrm{mol}^{-1}$ of $\mathbf{L}-1, \mathbf{L}-2$, and CI-II with subtilisin Carlsberg.

\begin{tabular}{llllll} 
& VDW & repulsion & dispersion & coulomb & total energy \\
\hline $\mathbf{I}-\mathbf{1}$ & 1423 & 2152 & -729 & -252 & 1171 \\
$\mathbf{I}-2$ & -108 & 413 & -521 & -147 & -255 \\
CI-II & -240 & 103 & -343 & 0 & -240 \\
\hline & VDW & repulsion & dispersion & coulomb & Docking energy \\
\hline $\mathbf{I}-\mathbf{1}$ & 1539 & $\mathbf{8 3 4}$ & -65 & 0 & 2308 \\
$\mathbf{I}-2$ & 28 & 34 & -59 & 0 & -3 \\
CI-II & 24 & 20 & -8 & 0 & 36 \\
\hline
\end{tabular}

Early reports of comparison of the complex of serine protease-protein inhibitor of subtilisin Carlsberg/eglin-C with $\alpha$-Chymotrypsin/enzyme inhibitor showed that the side chains of histidines and serines in the two active site can superimpose well, and that Asp-32 in subtilisin Carlsberg and Asp-102 in Chymotrypsin, have distinct positions and orientations. ${ }^{+10}$ Kinetics measurements showed that the selectivity of the $s-1$ ' subsite of alkaline protease and of Chymotrypsin are distinct also ${ }^{11}$, and the overall 
folding of molecules near the active site varies also. Cyclic peptide derivatives from CI-II with the disulfide bond at residues 53 and 70 and the peptide inhibitors eglin-C and $\mathrm{CI}-\mathrm{HI}$ involved formation of a tight enzyme-inhibitor complex. 9.11 At present only $\mathbf{I}-1$ can non-covalently interact with these two proteases with varied inhibition behaviors. As $I-1$ maintains the same structure at its backbone, $I$ - 1 can inhibit the two enzymes with varied inhibition type because of distinct hydrophobic and hydrophilic natures of the amino fits the active site of both enzymes and behavies as a competitive inhibitor.

In conclusion, in this work we demonstrated that by maintaining the interactive portion of enzyme inhibitors, peptide inhibitors with novel inhibition behavior can be obtained.

\section{Acknowledgment.}

Support for this research provided by the National Science Council, TAIWAN is gratefully acknowledged.

\section{References:}

1) Degrado, W.F., Adv. in Protein Chem. 1988, 39. 51.; Akerfeldt, K.S., Lear, J.D., Wasserman, Z.R., Chung, L.A., Degrado, W.F., Acc. Chem. Res. 1993, 26. 191.; Richardson, J.S.; Richardson, D.C. TIBS, 1989, July 14. 304.

2) Hann, K.W., Klis, W.A., Stewart, J.M. Science 1990, 248, 1544.; Schnolzer, M., Kent, S.B.H. Science 1992, 256, 221.Moser, R. Protein Engineering, 1992, 5(4), 323. Fasman, G.D. TIBS, 1989, July 14. 295. Thornton, J.M., Gardner, S. P. TIBS, 1989, July 14 300. Pessi, A., Bianchi, E., Crameri, A., Venturini, S., Tramontano, A., Sollazzo, M. Nature, 1933, 362. March 25, 367. Pantoliano, M.W., Whitlow, M., Wood, J.F., Rollence, M.L., Finzel, B.C., Gilliland, G.L., Poulos, T.L., Bryan, P.N. Biochem. 1988, 27, 8311.Shaw, G.S., Findlay, W.A., Semchuk, P.D., Hodges, R.S., Sykes, B.D. J. Amer. Chem. Soc. 1992, 114. 6258.

3). Leatherbarrow, R.J., Salacinski, H.J. Biochem, 1991, 30. 10717.

4). McPhalen, C. A., James, M. N. G. Biochem. 1988, 27, 6582-6598.; Bode, W., Paramokos, E., Musil, D. Eur. J. Biochem. 1987, 166, 673-692.

5). Bernstein, F. C., Koetzle, T. F., Williams, G. J. B., Meyer, Jr.E. F., Brice, M. D., Rodgers, J. R., Kennard, O., Shimanouchi, T., Tasumi, M. J. Mol. Biol., 1977, 112, 535-542..

6). Abola, E. E., Bernstein, F. C., Bryant, S. H., Koetzle, T. F., Weng, J.. "Protein Data Bank" in Crystallographic Databases-information Content, Software Syetem, Scientific Applications, eds. Allen, F. H., Bergerhoff, G., Sievers, R. Data Commission of the International Union of Crystallography, Bonn/Cambridge/Chester, 1987, pp107-132.

7). Schiller, P.W., Nguyen, T. M. -D., Miller, J., Int. J. Peptide protein Res. 1985, 25, 171.

8). Chen, S.T., Chen, H. J., Yu, H. M., Wang, K. T. Wang. J. Chem. Research. 1993, 228.

9). Felix, A.M., Wang, C.T., Heimer, E.P., Fournier, A., Int. J. Peptide Protein Res. 1988, 31, 231.

10).Mcphalen, C.A., Achnebli, H.P., James, M.N.G. FEBS letters, 1985, 188, 55.; Takeuchi, Y., Noguchi, S., Satow, Y., Kojima, S., Kumagai, I., Miura, K., Nakamura, K.T., Mitsui, Y., Protein Engineering, $1991,4(5), 501$.

11).Morihara, K., Oka, T., Arch. Biochem. Biophy. 1977, 178, 188.; Pattabiraman, T.N., Lawson, W.B., Biochem. J., 1972, 126, 645.; Bratovanova, E.K., Petkov, D.D., Biochem. J. 1987, $248,957$.

(Received in USA 23 March 1994; accepted 3 August 1994) 